\title{
Política econômica do segundo governo FHC: mudança em condiçõesadversas
}

\author{
Gesner Oliveira \\ Frederico Turolla
}

\section{Estabilização com desequilíbrio: a "herança de FHC para FHC"}

0 ano de 1994 marcou uma mudança de longo alcance na economia brasileira. A pós uma série de planos de estabilização fracassados, o Plano R eal obteve o primeiro sucesso na contenção da expansão do nível dos preços que, desde os anos de 1980, já podia ser caracterizada como uma superinflação.

0 elemento essencial da estratégia do Plano R eal foi o sucesso na introdução de um mecanismo de neutralização da inércia inflacionária. A implementação gradual da troca de moedas por meio da U nidade $R$ eal de Valor (U RV), assegurando aos agentes econômicos de que não haveria quebra de contratos, como os que foram utilizados em planos anteriores, forneceu o mecanismo de transição para uma taxa de inflação de um dígito.

0 componente principal da estratégia de neutralização da inércia inflacionária foi a ancoragem dos preços domésticos nos preços internacionais, que levou a uma apreciação da taxa de câmbio. I sso foi posśivel graças ao fato de que naquele momento os países emergentes encontravam uma situação de razoável liquidez nos mercadosinternacionais de capitais. Essa abundância permitiu o financiamento dos déficits crescentes em conta corrente decorrentes da mudança cambial, somada à aceleração da redução das alíquotas de importação. 
A política econômica do primeiro mandato de Fernando Henrique C ardoso (1995-1998) deu absoluta ênfase à consolidação do ambiente de estabilidade de preços. Durante todo o período, foi mantido um regime cambial semifixo, baseado na administração de estreitas bandas de flutuação. Permitiu-se uma desvalorização cambial a um ritmo relativamente estável, porém insuficiente para a redução do desequilíbrio do mercado em relação ao câmbio real de equilíbrio.

Sob um regime de câmbio administrado, a política monetária perdeu autonomia e ficou condicionada à manutenção da paridade de câmbio escolhida. A manutenção da valorização cambial requer, geralmente, contração monetária, especialmente quando ocorrem choques externos negativos que afetam a oferta internacional de divisas para o país.

$N$ esse sentido, os efeitos negativos do regime cambial semifixo sobre a política monetária foram agravados pela ocorrência de pelo menos três grandes crises de países emergentes com impacto direto sobre a economia brasileira: as crises mexicana, asiática e russa. Entre as medidas defensivas, voltadas para a continuidade da rolagem do estoque de dívida pública, a gestão da dívida mobiliária federal doméstica passou a migrar em direção a um incremento dos títulos pós-fixados em sua composição. N os períodos de crise foram promovidas contrações monetárias para evitar que a saída de divisas em larga escala ameaçasse a defesa do regime de bandas cambiais. Por sua vez, a severidade do impacto das crises sobre a economia brasileira esteve diretamente relacionada à maior exposição e vulnerabilidade do país perante o mercado internacional de capitais.

A recorrente contração monetária teve efeitos também sobre a situação fiscal. 0 aumento da carga de juros sobre a dívida pública constituiu fonte adicional de expansão fiscal. $\mathrm{N}$ o final do primeiro mandato houve aumento do déficit primário, gerado pelo desequilíbrio da situação primária do setor público. A deterioração dos dois componentes do déficit público, o déficit primário e a despesa de juros, produziu um quadro de instabilidade fiscal insustentável.

D urante o primeiro mandato, os esforços de política fiscal foram canalizados para uma proposta de reforma estrutural, especialmente com a tentativa de aprovação de emendas constitucionaise de legislação voltada para a redução do déficit previdenciário e alterações na estrutura administrativa do setor público, além de ações patrimoniais como a privatização e o reconhecimento de passivos contingentes. Adicionalmente, o governo federal envidou esforços para conter a expansão fiscal dos governos subnacionais. 
Verificou-se, entretanto, menor empenho quanto ao controle direto de receitas e despesas no nível primário. A ssim, o resultado fiscal deteriorou-se nesse período, especialmente diante da oposição política enfrentada no Congresso às principais medidas de ajuste que envolviam mudanças constitucionais ou infraconstitucionais.

0 aparato de política econômica do primeiro mandato foi bem sucedido no tocante à consolidação da estabilidade de preços, tendo logrado produzir deflação em alguns índices de preços ao consumidor, mas mostrou-se insustentável devido à acumulação contínua de passivos públicos e externos. 0 ritmo de acumulação da dívida pública e do passivo externo mostraram-se insustentáveis, caracterizando o primeiro mandato $\mathrm{FHC}$ como um período de estabilização com desequilíbrio. Essa "herança de FHC para FHC" restringiu o raio de ação da política econômica do segundo mandato, mesmo com a mudança do regime cambial.

\section{A tríplice mudança de regime no segundo mandato}

U ma análise cuidadosa da política econômica do período FH C desa conselha caracterizá- la como uma estratégia uniforme ao longo do tempo, uma vez que acusou sensível reorientação no segundo mandato.

0 regime de política econômica do primeiro mandato foi substituído a partir do fim de 1998 e começo de 1999. 0 Q uadro 1 sumaria as características dos regimes fiscal, monetário e cambial no primeiro mandato e as mudanças verificadas no segundo mandato, destacando a data efetiva em que estas ocorreram; dessa forma, as al terações não necessariamente coincidem de forma precisa com a cronologia dos mandatos.

A ssim, no período de 1995 a 1998, o efforço de estabilização veio acompanhado de desequilíbrios fiscais e externos. U m importante passo na direção da reversão desses desequilíbrios foi dado em 1999. Promoveu-se naquele ano uma tríplice mudança de regime, envolvendo os regimes cambial, monetário e fiscal:

- 0 regime de câmbio fixo, flexibilizado pelas bandas cambiais, foi substituído por uma flutuação suja, na qual o Banco C entral manteve a intervenção na forma de venda pontual de reservas e oferta de títulos públicos indexados à taxa de câmbio.

- 0 regime monetário, anteriormente atrelado à defesa das bandas cambiais, foi substituído pelo sistema de metas inflacionárias. 
- 0 regime fiscal foi alterado a partir da introdução, no fim de 1998, de um compromisso de política econômica relativo à manutenção de um superávit primário elevado o suficiente para produzir a estabilização da razão entre a dívida pública e o Produto Interno Bruto (PIB).

QUADRO 1

P rincipais M udanças no R egime de P olítica E conômica no S egundo M andato (1999-2002)

\begin{tabular}{|c|c|c|c|}
\hline & SITUAÇÃO NO 1 Q M ANDATO & DATA EFETIVA DA MUDANÇA & MUDANÇAS NO $2^{\circ}$ MANDATO \\
\hline $\begin{array}{l}\text { REGIME } \\
\text { FISCAL }\end{array}$ & $\begin{array}{l}\text { •Esforços de reforma estrutural e patrimo- } \\
\text { nial do setor público, com a apresentação } \\
\text { de propostas legislativas e privatização. } \\
\text { •Introdução de medidas de controle das } \\
\text { finanças dos governos estaduais e munici- } \\
\text { pais, com efeito estrutural, mas resultados } \\
\text { não-imediatos. } \\
\text { •C ontrole primário insuficiente: aumento } \\
\text { do déficit primário. } \\
\text { •Aumento da despesa com juros devido à } \\
\text { instabilidade financeira. }\end{array}$ & $\begin{array}{l}28 \text { de outubro de } 1998 \text { (anúncio do Pro- } \\
\text { grama de E stabilidade F iscal). }\end{array}$ & $\begin{array}{l}\text {-Ajuste fiscal voltado para a gera- } \\
\text { ção de superávits primários, basea- } \\
\text { do em aumento de receitas e re- } \\
\text { dução de despesas, com maior } \\
\text { ênfase nas primeiras. } \\
\text {-Fadiga reformista, embora propos- } \\
\text { tas importantes tenham sido im- } \\
\text { plementadas (Lei de R esponsabi- } \\
\text { lidade Fiscal, fator previdenciário). }\end{array}$ \\
\hline $\begin{array}{l}\text { REGIME } \\
\text { MONETÁRIO }\end{array}$ & $\begin{array}{l}\text {-Subordinado à âncora cambial. } \\
\text { •C hoques externos requereram contra- } \\
\text { ção monetária recorrente. }\end{array}$ & $\begin{array}{l}12 \text { de janeiro de } 1999 \text { (relaxamento da } \\
\text { âncora cambial) e maio de } 1999 \text { (introdu- } \\
\text { ção do regime de metas de inflação). }\end{array}$ & $\begin{array}{l}\text { •M etas de inflação, possibilitando } \\
\text { resposta mais suave aos choques. }\end{array}$ \\
\hline $\begin{array}{l}\text { REGIME } \\
\text { CAMBIAL }\end{array}$ & $\begin{array}{l}\text {-C âmbio administrado. } \\
\text { •D éficits crescentes em conta corrente. }\end{array}$ & $\begin{array}{l}12 \text { de janeiro de } 1999 \text { (abandono da defe- } \\
\text { sa das bandas cambiais). }\end{array}$ & $\begin{array}{l}\text { •Flutuação suja. } \\
\text { •R eversão dos déficits em conta } \\
\text { corrente. }\end{array}$ \\
\hline
\end{tabular}

A tríplice mudança de regime foi sedimentada com a assinatura de um acordo com o Fundo M onetário Internacional (FM I), em 1998. Embora tenham sido em grande parte anteriores ao acordo com o Fundo, as novas diretrizes de política foram transformadas em compromissos de desempenho no âmbito do acordo e de suas revisões subseqüentes.

O sitens a seguir analisam a tríplice mudança no regime de política econômica ocorrida no segundo mandato de Fernando $\mathrm{H}$ enrique $\mathrm{C}$ ardoso.

\section{A mudança do regime fiscal}

N o primeiro mandato, o foco das ações na área fiscal voltou-se para as ações de alcance estrutural. Entretanto, a maior parte das iniciativas dessa 
natureza sucumbiu à forte resistência legislativa e política. Entre as iniciativas fiscais do primeiro mandato, as mais importantes foram as propostas de emenda constitucional - conhecidas como R eforma da Previdência e R eformaAdministrativa - ; a lei que possibilitou o refinanciamento de dívidas estaduaise municipais; o ajuste patrimonial por meio de privatizações; e o reconhecimento de passivos contingentes (os chamados "esqueletos").

Entre as iniciativas de reforma estrutural que lograram resultados, destaque- se o disciplinamento das finanças dos governos estaduais e municipais, possibilitado pela Lei $n-9.496 / 97$, que instituiu os acordos de refinanciamento das dívidas estaduaise municipaisjunto à U nião. 0 sacordos de transferência de dívida vieram acompanhados de compromissos de pagamento do débito junto ao governo federal que, na prática, resultaram em uma limitação para a expansão indiscriminada do déficit público fora da esfera federal. N ote-se que o processo de socorro do Governo federal aos governos subnacionais foi recorrente na história brasileira das últimas décadas, com a conta sendo invariavelmente transferida aos contribuintes da U nião. Embora os resultados dos acordos não tenham aparecido no primeiro mandato, contribuíram para a disciplina fiscal que se implantou no período posterior.

Em conseqüência, as finanças públicas deterioraram durante o primeiro mandato. 0 déficit primário aumentou, especialmente apósa crise asiática, em 1997, que reduziu a arrecadação tributária dos diversos governos de maneira geral. A o mesmo tempo, a resposta às crises internacionaismediante aumento de juros internos, como forma de manter o regime de âncora cambial em funcionamento, fez crescer a despesa com juros pelo setor público. A pós as crises da Ásia e da R ússia, a situação fiscal do período entrou em um círculo vicioso no qual a própria piora do déficit causava uma redução na confiança do pás, que se refletia em maior prêmio de risco, maiores jurose ulterior agravamento da crise fiscal.

0 segundo mandato foi marcado por mudanças na área fiscal. Essas mudançastiveram início em parte ainda durante o primeiro mandato, mas, devido a seu al cance, só foram apresentar resultados no período posterior. A principal alteração, de impacto imediato, foi a introdução do Plano de Estabilidade Fiscal, em outubro de 1998, que passou a estipular o patamar de superávit primário do setor público necessário para a estabilização da razão dívida/ produto. Foram criadas metas de superávit primário, desenhadas para estabilizar a razão entre a Dívida Líquida do Setor Público (D LSP) e o PIB. Segundo Giambiagi, 
[...] embora houvesse dificuldades inegáveis para viabilizar politicamente uma estratégia fiscal ortodoxa, o fato é que as autoridades não exibiram o mesmo rigor, antes de 1998, na ado ção de mecanismos de controle das contas públicas, 0 que veio a se revelar depois, a partir de 1999, no contexto da crise externa e fiscal que gerou a necessidade de negociar o acordo com o FM I no final de 1998/ início de 1999 (2002, p. 39).

O programa está na origem da recuperação da confiança na economia brasileira após a desvalorização cambial de 1999.

A Figura 1 evidencia a mudança no padrão de austeridade fiscal ocorrida no segundo mandato a partir do Programa de Estabilidade Fiscal.

FIGURA 1

$\mathrm{N}$ ecessidades de F inanciamento do Setor Público (acumulado em doze meses, em \% do PIB )

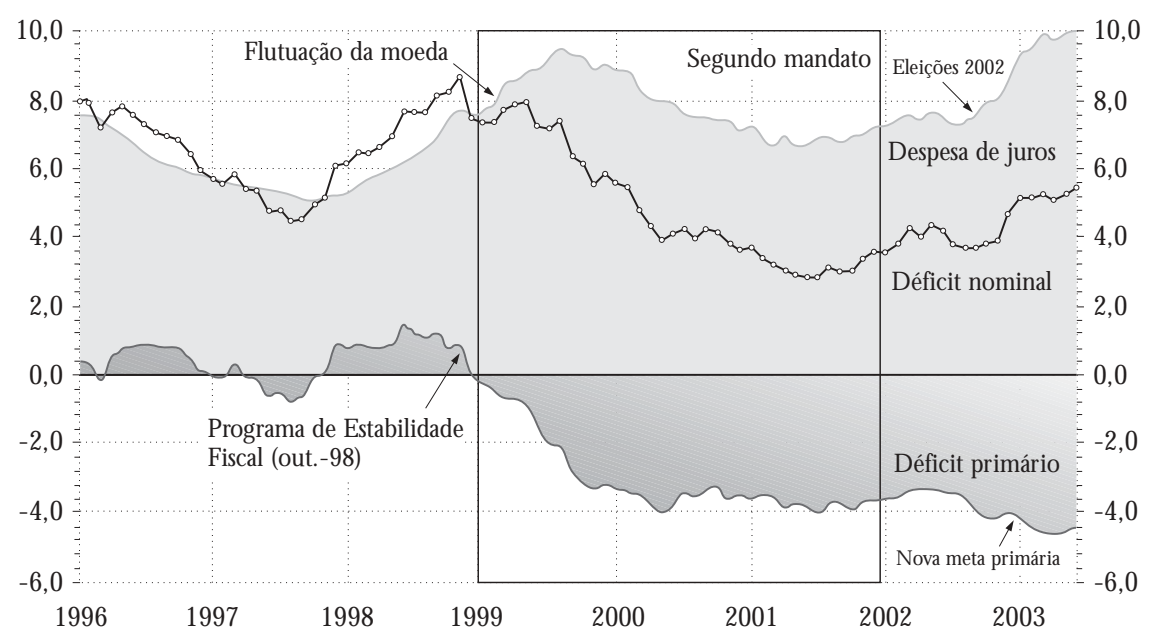

F onte: Elaboração dos autores a partir de dados primários disponíveis em Banco C entral (www.bcb.gov.br), obtidos em agosto de 2003.

A lém do Programa de Estabilidade Fiscal, chamam atenção os seguintes pontos:

- A pós a recuperação da crise de 1999 e a retomada da confiança na economia, para a qual contribuiu a mudança no superávit primário, a despesa financeira do setor público apresentou declínio até meados de 2001. $\mathrm{N}$ aquele momento teve início novo ciclo de contração monetária, relacionado a diversos choques internos e externos, intensificados pela instabilidade gerada pelo ciclo eleitoral. 
- 0 déficit total do setor público passou a diminuir a partir de meados de 2001.

- O Programa de Estabilidade Fiscal foi baseado maisfortemente na elevação de receitas, enquanto as despesas continuaram crescendo. Em conseqüência, a carga tributária cresceu durante o período. Em parte, esse comportamento pode ser creditado à dificuldade política envolvida na aprovação de reformas estruturais e medidas voltadas para a contenção de despesas. Esse movimento corresponde a uma mudança da composição da despesa pública, com menos investimento e mais custeio, devido à necessidade de manobra na parcela do orçamento sob o controle discricionário do governo.

- O s esforços de reforma estrutural continuaram a ser perseguidos no segundo mandato, embora mostrando fadiga em relação ao primeiro governo. Em especial, o arcabouço institucional e operacional das finanças públicas no segundo mandato foi completado com a Lei de R esponsabilidade Fiscal. Além disso, foi possível aprovar o Fator Previdenciário do IN SS e uma parte da R eforma A dministrativa.

- O s gastos sociais mantiveram, durante o segundo mandato, o patamar mais elevado atingido no fim do primeiro mandato. A Figura 2 apresenta a evolução dos gastos sociais nos dois mandatos.

FIGURA 2

$\mathrm{G}$ asto Social F ederal (valores em bilhões de reais de dez embro de 2001, atualiz ação pelo IG P-D I)

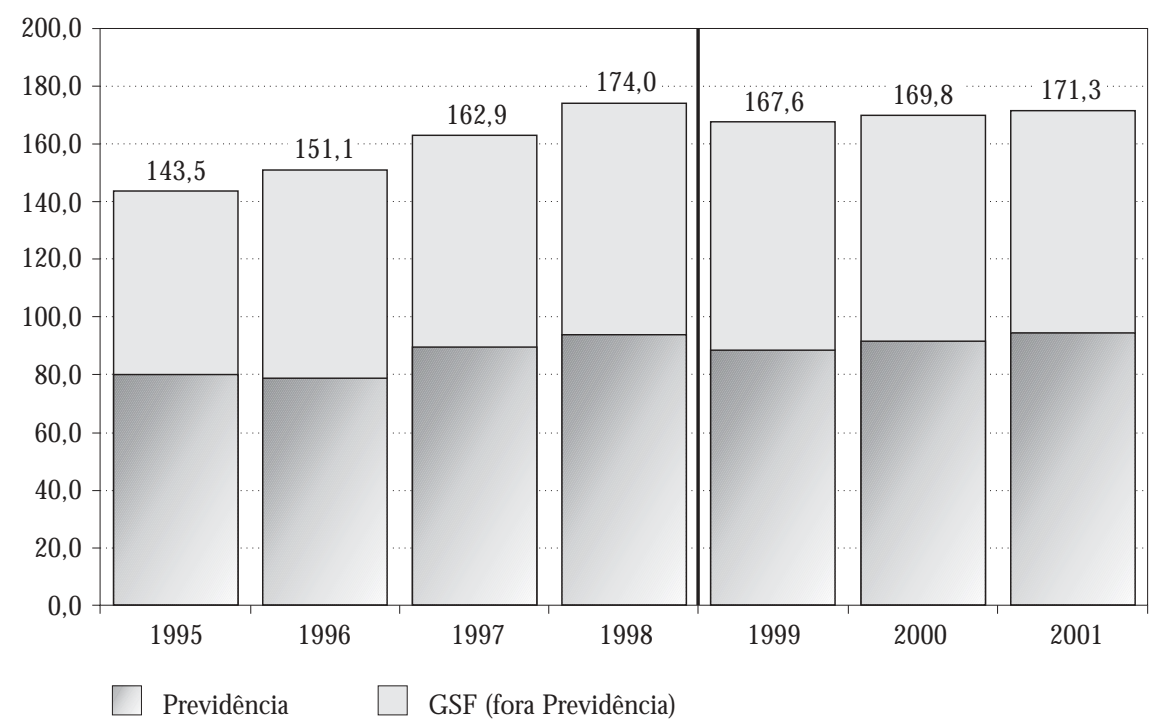

Fonte: C astro et al. (2003). 


\section{A mudança do regime cambial}

N o primeiro mandato, a ancoragem cambial foi um elemento essencial da consolidação da estabilidade de preços. $\mathrm{N}$ a realidade, a experiência de vários processos de estabilização de hiperinflações mostrou que o câmbio constitui elemento essencial de estratégias de estabilização em tais circunstâncias. 0 problema no caso brasileiro foi sua duração excessiva.

Como resultado da âncora cambial e da conseqüente apreciação do câmbio, o saldo em transações reais experimentou deterioração quase contínua durante o Plano R eal. 0 superávit evaporou rapidamente com a apreciação da taxa de câmbio no segundo semestre de 1994, o que se somou a uma intensificação do ritmo de crescimento com a estabilização dos preços. De um superávit de U $\$ \$ 4,8$ bilhões em 1994 , o país passou a um déficit de U S\$10,9 bilhões em 1995, o qual se aprofundou daí em diante. De fevereiro de 1997 a janeiro de 1998, esse déficit atingiu o seu pico histórico de U $\$ \$ 19,7$ bilhões.

D urante esse período, que combina maior abertura comercial com valorização cambial intensa, o ritmo de crescimento das exportações e importações foi ainda mais díspar que no período anterior. Comparando-se 0 ano de 1998 com os doze mesesterminadosem junho de 1994, portanto o período que vai do lançamento do $R$ eal até a sua flutuação, as exportações de bens e de serviços apresentaram um crescimento de 32,3\%, enquanto as importações expandiram-se em 105,1\%.

Ao mesmo tempo, durante o período de câmbio administrado, intensificou-se a acumulação de passivos externos na forma de dívida e de capital produtivo estrangeiro, com grande peso de endividamento de curto prazo, gerando pagamentos cada vez maiores na conta de rendas. Tal processo estava, em grande medida, associado à necessidade de recomposição das reservas internacionais, fornecendo munição ao Banco C entral em sua tarefa diária de estabilizar o câmbio dentro das estreitas bandas de flutuação.

0 período foi, portanto, marcado por uma combinação insustentável. De um lado, o saldo em transações reais deteriorou-se em função da economia mais aberta com taxa de câmbio apreciada. D e outro lado, o regime cambial levou a uma acumulação de passivos externos, resultando em despesas crescentes na conta de rendas. 0 bservou-se, em conseqüência, uma deterioração quase contínua do saldo em transações correntes durante o período do Plano R eal. 0 déficit em conta corrente saltou de 
menos de U S\$2 bilhões em 1994 para níveis superiores a U S\$33 bilhões no fim de 1998, superando $4 \%$ do PIB.

A mudança do regime cambial ocorreu nos primeiros dias do segundo mandato. 0 sistema de bandas deu lugar a um regime de flutuação suja. $A$ principal conseqüência positiva da introdução do regime flexível a partir de 1999 foi a possibilidade de ajuste na conta corrente.A reversão do déficit em conta corrente deu-se não apenas em função do câmbio real mais depreciado, mas também pela reversão do crescimento das remessas de rendas ao exterior no novo regime de política econômica.

A Figura 3 mostra a evolução dos dois componentes principais da conta corrente do balanço de pagamentos: as transações reais ${ }^{1}$ e as rendas. As setas indicam as tendências relativas aos dois componentes em cada um dos períodos relevantes. Enquanto o período de câmbio administrado corresponde a uma situação duplamente explosiva, em que tanto o saldo de transações reais quanto as rendas deterioram-se simultaneamente, após a tríplice mudança de regime em 1999 ocorre uma estabilização do nível das rendas aliada à melhora nas transações reais.

\section{FIGURA 3}

Saldo em Transações $R$ eais e em $R$ endas (em bilhões de dólares, acumulados em doze meses)

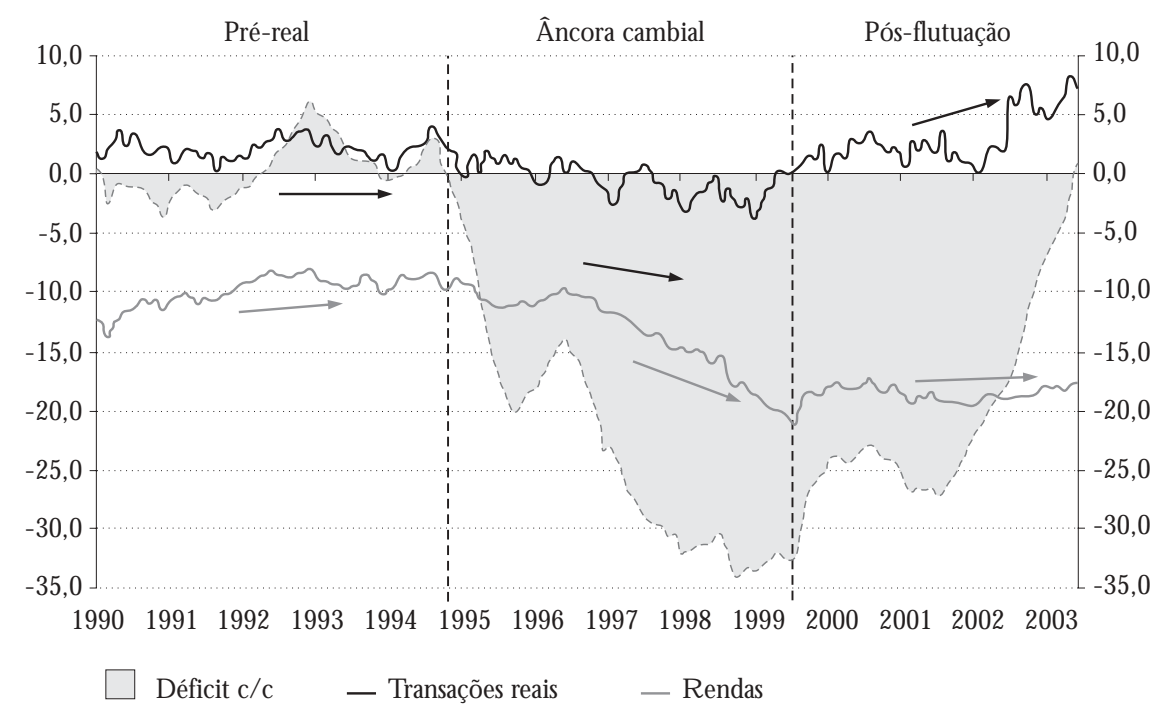

F onte: Elaboração dos autores a partir de dados primários disponíveis em Banco C entral (www.bcb.gov.br), obtidos em agosto de 2003.

A acumulação de dívida externa gerada pelo regime de bandas cambiais provocou um aumento no volume de rendas, ou serviços de fatores
1. As transações reais, conforme Bresser Pereira(2001), correspondem à soma da balança comercial com a balança de serviços, ou seja, todo o fluxo de comércio de bense de serviçosnão-fatores. $A$ agregação desses dois itens traz a conveniência de separar a parte da conta corrente que é afetada pela política econômica contemporânea, em especial pela política cambial, já que as rendas e as transerênciasunilateraisapresentam maior rigidez em relação ao nível da taxa de câmbio e da atividade econômica. 
liquidamente remetidos ao exterior. A partir da flutuação cambial, esses pagamentos estabilizaram-se em um patamar entre U S\$17 bilhões e U S\$19 bilhões e vêm apresentando ligeira melhora. Assim, a partir do ano de 1999 ocorreu uma combinação da estabilização dos pagamentos relativos aos serviços de fatores com uma queda no sal do dos bens e serviços não- fatores. Essa combinação explica a redução do déficit em conta corrente, que chegou a U \$ \$7,7 bilhões no fim do segundo mandato; e, nos primeiros meses de 2003, passou a apresentar pequenos superávits.

0 ajuste das transações reais relaciona-se mais diretamente ao saldo da balança comercial. Suas causas são a depreciação cambial recente e o fraco ritmo de expansão da atividade econômica doméstica. Entretanto, a meIhoria não se limitou aos benstangíveis. 0 saldo em serviços, que, na nova metodologia, só inclui os serviços não-fatores, vem registrando contribuição importante, igualmente relacionada ao comportamento do câmbio e ao ritmo da economia. As transferências unilaterais, menos sensíveis ao câmbio, também apresentaram melhora ainda que em menor escala.

A mudança no saldo em conta corrente processou-se, portanto, sob a liderança do comércio exterior de bens e de serviços, dada a estabilidade no saldo de rendas. U ma parcela significativa do ajuste pode ser atribuída à baixa absorção interna da economia. Esta última restringe as importações, enquanto a taxa de câmbio depreciada atua tanto do lado de dentro como fora das fronteiras nacionais, elevando a competitividade dos produtos brasileiros nos mercados interno e externo. Entretanto, a magnitude do ajuste sugere algum movimento estrutural relacionado aos fluxos de comércio exterior.

0 regime cambial flexível implantado a partir de 1999 não pode ser considerado de flutuação pura. A intervenção no mercado cambial tem sido realizada por vários instrumentos, entre os quais se destaca a continuidade em manter a dívida indexada à taxa de câmbio, mediante a oferta primária de títulos públicos (N BC - E e N T N - D) e, mais recentemente, a oferta de swaps cambiais.

Asintervenções diretas no mercado cambial não se restringiram acompras e vendas pontuais, mas chegaram a ser operacionalizadas pela venda de um montante fixo de divisas, que ficou conhecida como "ração diária" em um momento de baixa liquidez do mercado. 0 Banco Central também atuou oferecendo linhas de comércio exterior de forma a compensar a escassez causada pelas incertezas associadas ao ambiente político com 0 advento das eleições de 2002. 


\section{A mudança do regime monetário}

0 relaxamento da âncoracambial, no início de 1999, trouxe preocupa ções quanto ao recrudescimento do processo inflacionário. N aquele momento, não era possível antecipar, com um grau razoável de segurança, pelo menos duas variáveis relevantes: o novo nível de equilíbrio da taxa de câmbio e o coeficiente de repasse da desvalorização cambial para o nível de preços. A incerteza permitiu inclusive o surgimento de previsões catastrofistas de até $50 \%$ de inflação naquele ano.

A retomada da estabilidade das expectativas de inflação foi facilitada por uma série de fatores, entre eles:

- O próprio ambiente de preços estáveis que, naquele momento, já perdurava por quatro anos e meio, e que explica a relativa desindexação da economia por ocasião da troca de regime cambial.

- 0 resultado positivo da safra agrícola de verão, que continuava a se expandir em resposta a uma política agrícola bem-sucedida no tocante à ampliação da oferta exportável.

- O s ganhos de eficiência associados à maior exposição da economia ao mercado mundial.

- 0 ambiente recessivo da economia, combalida pela crise da R ússia des de o segundo semestre de 1998.

- A rápida recomposição no comando da área econômica após a crise que culminou com a mudança do regime cambial.

Enquanto no primeiro mandato a política monetária atuava de forma subordinada às necessidades de fluxo cambial ditadas pela defesa do regime semifixo, no novo ambiente, a política monetária ganhou graus de liberdade. A nova âncora para as expectativas inflacionárias passou a ser 0 regime de metas de inflação medidas pelo IPC A. Estas, por sua vez, passaram a serem definidas pelo C onselho $\mathrm{M}$ onetário $\mathrm{N}$ acional e executadas pelo Banco C entral.

A Figura 4 mostra o comportamento do IPCA desde a introdução do regime de metas. Pode-se verificar que o regime alcançou um razoável sucesso nos dois primeiros anos; a inflação manteve-se dentro do interva lo estipulado em seu primeiro ano, 1999, e no ano 2000 atingiu o centro do intervalo de metas. Em 2001 e 2002, sob choques externos e internos de elevada magnitude, a reação da política monetária foi menos eficiente para assegurar o cumprimento das metas. 
FIGURA 4

C umprimento das M etas de Inflação (IPC A , variação percentual em doze meses)

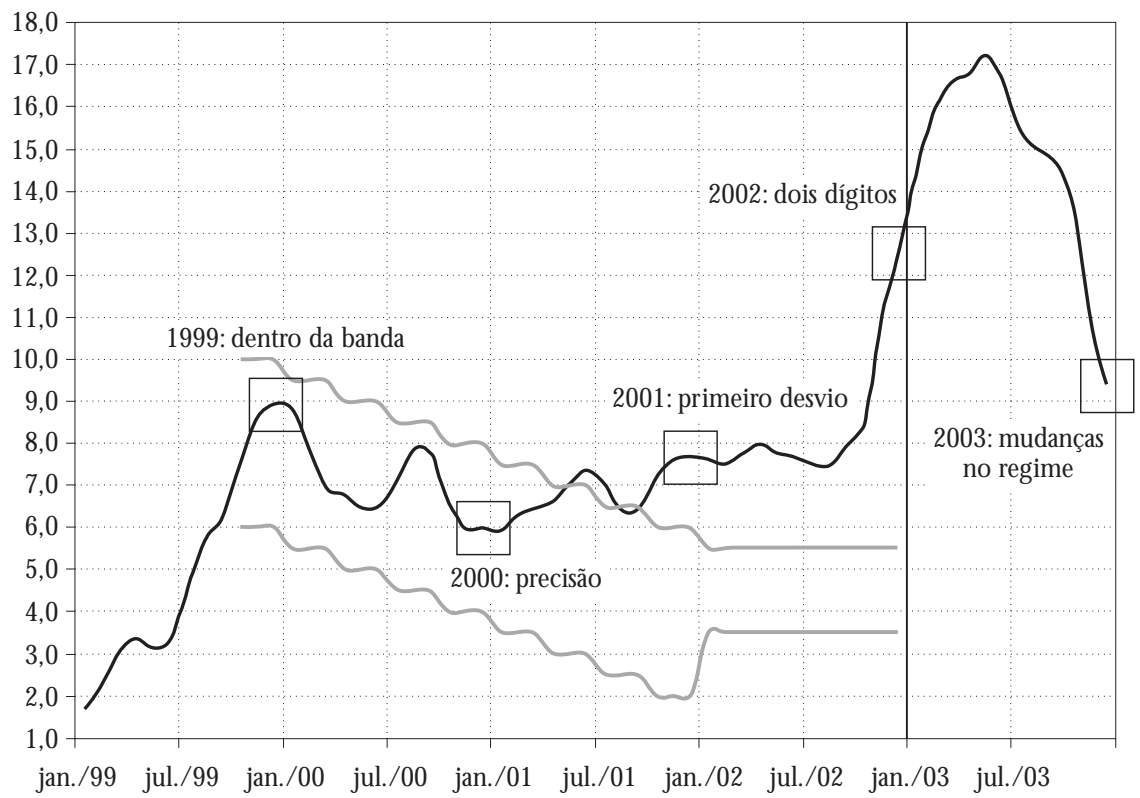

O bs: : Entre agosto e dezembro de 2003 foram utilizadas as expectativas médias do mercado financeiro. F onte: Elaboração dos autores a partir de dados primários disponíveis em IBGE (www.ibge.gov.br), e Banco C entral (www.bcb.gov.br), obtidos em agosto de 2003. O s dados do IPCA foram obtidos no site do IBGE e as metas de inflação, no site do BCB; as projeções foram acumuladas a partir da pesquisa de expectativas realizada pelo Banco $C$ entral junto a instituições financeiras.

A principal conseqüência da substituição do regime monetário subordinado à âncora cambial pelo de metas de inflação foi a redução tanto do nível como da volatilidade das taxas de juros. A Figura 5, que apresenta a evolução das taxas de juros e de câmbio entre janeiro de 1995 e agosto de 2003, evidencia que a taxa primária de juros passou a apresentar menor nível e menor volatilidade após a tríplice mudança de regime em 1999. A o mesmo tempo, a taxa de câmbio passou a absorver os choques externos e, portanto, tornou-se mais volátil que no regime anterior.

\section{A efetividade da política econômica no segundo mandato \\ Limitaçöes: ambiente financeiro e herança dos desequilíbrios}

0 segundo mandato teve início em ambiente turbulento. N os primeiros dias do novo governo, o estado de $M$ inas Gerais anunciou que não honraria o pagamento de um bônus vincendo, causando incerteza no mercado financeiro. 0 regime de câmbio administrado, já combalido pelas saídas de capital, quase contínuas desde a crise asiática, sucumbiu à pressão 
e foi abandonado. Simultaneamente, o quadro institucional da política econômica foi abalado pelo pedido de demissão da diretoria do Banco C entral. Formaram-se expectativas negativas quanto à solvência da economia brasileira, sobretudo nos mercados financeiros internacionais.

\section{FIGURA 5}

C âmbio e Juros nos D ois M andatos (dados diários de taxa Selic, em \% ao ano, e taxa de câmbio em reais por dólar)
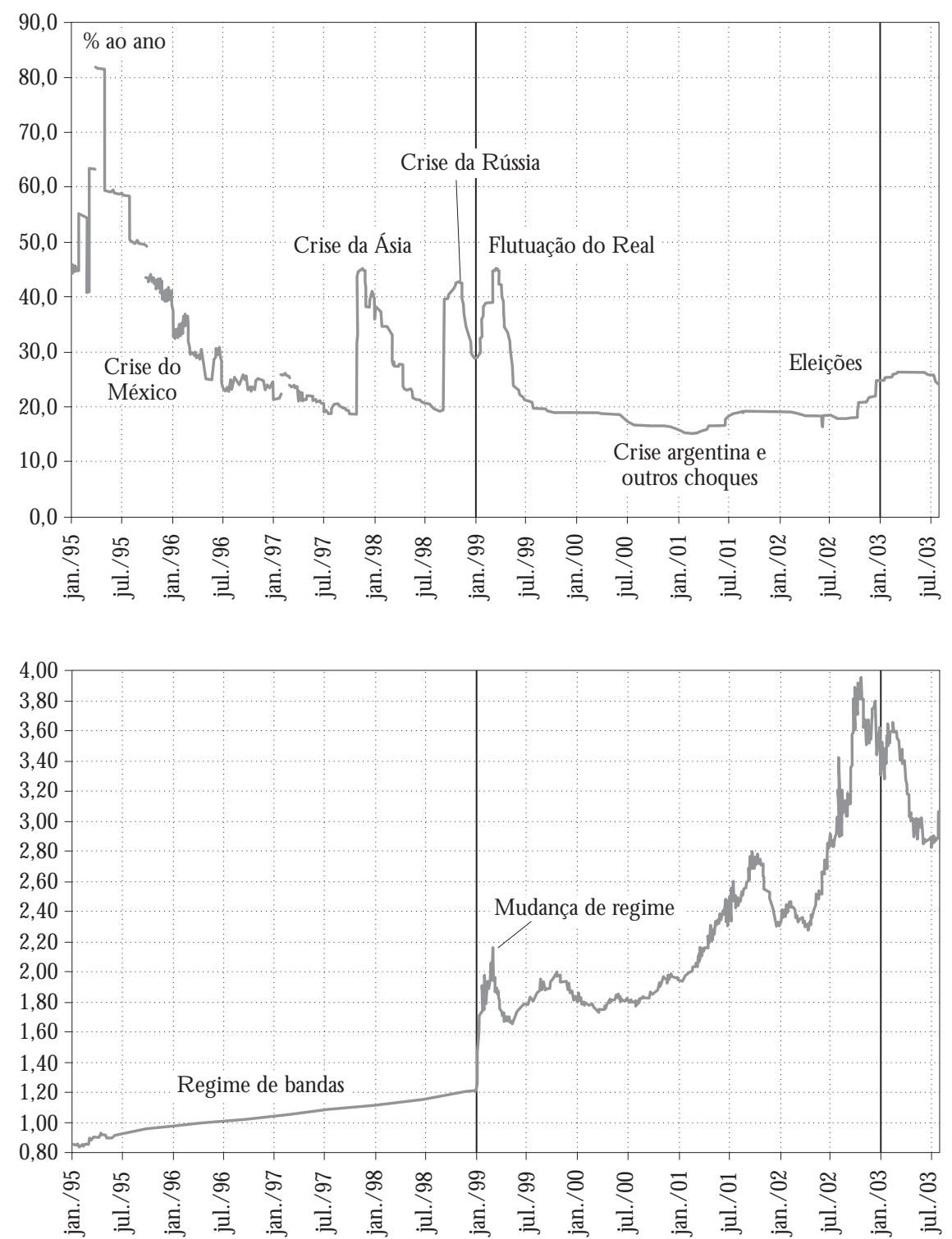

F onte: Elaboração dos autores a partir de dados disponíveis no sistema de recuperação de séries históricas em Banco C entral (www.bcb.gov.br), obtidos em agosto de 2003. 
2. Este ponto foi ressaltado em Oliveira (1999).
A desvalorização de 1999 corresponde a um choque de termos de troca e imediatamente fomentou a discussão so bre o seu repasse para a inflação. A experiência negativa do M éxico quando flutuou o câmbio em 1995 serviu de guia ou de pretexto para a reação dos mercados financeiros, que anunciaram projeções de inflação de até 50\%. Entretanto, tais projeções careciam de fundamentos teóricos e empíricos² . Seria natural esperar que a alteração de um dos macropreços mais importantes, a taxa de câmbio, gerasse ruído no conjunto da economia, com aumento do preço relativo dos bens e serviços comerciáveis, especialmente as commodities, em relação àqueles não-comerciáveis, como os serviços. M as o ajuste não é automático, de forma que a acomodação costuma ser marcada por oscilações e incertezas. A própria estabilização da taxa de câmbio no seu novo nível de equilíbrio costuma ser precedida de variações significativas (overshooting), superiores àquelas que terminam por prevalecer no médio prazo.

Porém, não haveria porque esperar, naquele momento, a volta da inflação crônica que flagelou o país por meio século até o Plano R eal. 0 utras experiências similares demonstram que depreciações significativas da moeda nacional não vêm necessariamente acompanhadas de inflação na mesma proporção. N a C oréia, o coeficiente de transmissão da mudança do câmbio à inflação foi relativamente baixo, em torno de 17\%. 0 liveira (1999) realizou o seguinte cálculo: transplantado para o Brasil e supondo um novo câmbio de equilíbrio 30\% superior à média de 1994-1998, se teria uma inflação em torno de 5\%, inferior à média anual de crescimento dos preços em to das as décadas desde os anos de 1940. Esse cálculo simples evidencia que muitas das manifestações catastrofistas possivelmente estavam relacionadas a um comportamento oportunístico de agentes, aproveitando- se da incerteza e da falta de parâmetros para a avaliação tanto do novo nível de câmbio como do coeficiente de repasse.

A recuperação do país diante da crise de 1999 desmentiu as previsões mais pessimistas. $\mathrm{N}$ ão houve ruptura na rolagem da dívida pública; a inflação ao consumidor acumulada em doze meses não saiu da casa de um dígito e o PIB não apresentou queda em termos reais no ano. A pós a recuperação da crise cambial, verificou-se um período de relativa estabilidade financeira que atravessou o ano 2000. N aquele período, a taxa de câmbio flutuou ao redor do patamar de $\mathrm{R} \$ 1,80$ por dólar e os juros permaneceram em queda. Atingiu-se no dia 15 de março de 2001 o patamar mais baixo em termos nominais da história da taxa Selic, de 15,1\% ao ano. A 
relativa calmaria foi interrompida ainda no primeiro trimestre do ano 2001, quando a taxa Selic retomou um movimento de alta.

A reversão do bom momento vivido pelaeconomiabrasileirafoi causada por uma combinação de choques adversos nos terrenos externo e doméstico: a crise de oferta de energia elétrica ("apagão" ), a desaceleração da economia norte-americana, a crise da economia argentina, os atentados de 11 de setembro e os escândalos contábeis que afetaram empresas norte-americanas. Tal sucessão de eventos depreciou fortemente o câmbio e fez retrair os investimentos produtivos.

Em 2002, asincertezas externas e os efeitos da recessão nosinvestimentos foram acrescidas de fatores de incerteza relacionadosà proximidade daseleições. Logo após o lançamento da campanha presidencial, dessa vez mais cedo que osanteriores, as expectativasinflacionárias deterioraram- se de forma perceptível. A Figura 6 evidencia que a expectativa média do mercado financei ro para a inflação nos doze meses seguintes rompeu a relativa estabilidade apresentada até meados daquele ano, chegando a níveis alarmantes. Essas expectativas só foram revertidas com a posse do novo governo.

FIGURA 6

Expectativas I nflacionárias e a E leições de 2002 (previsão média do mercado financeiro para 0 IPC A em doz e meses, em \%)

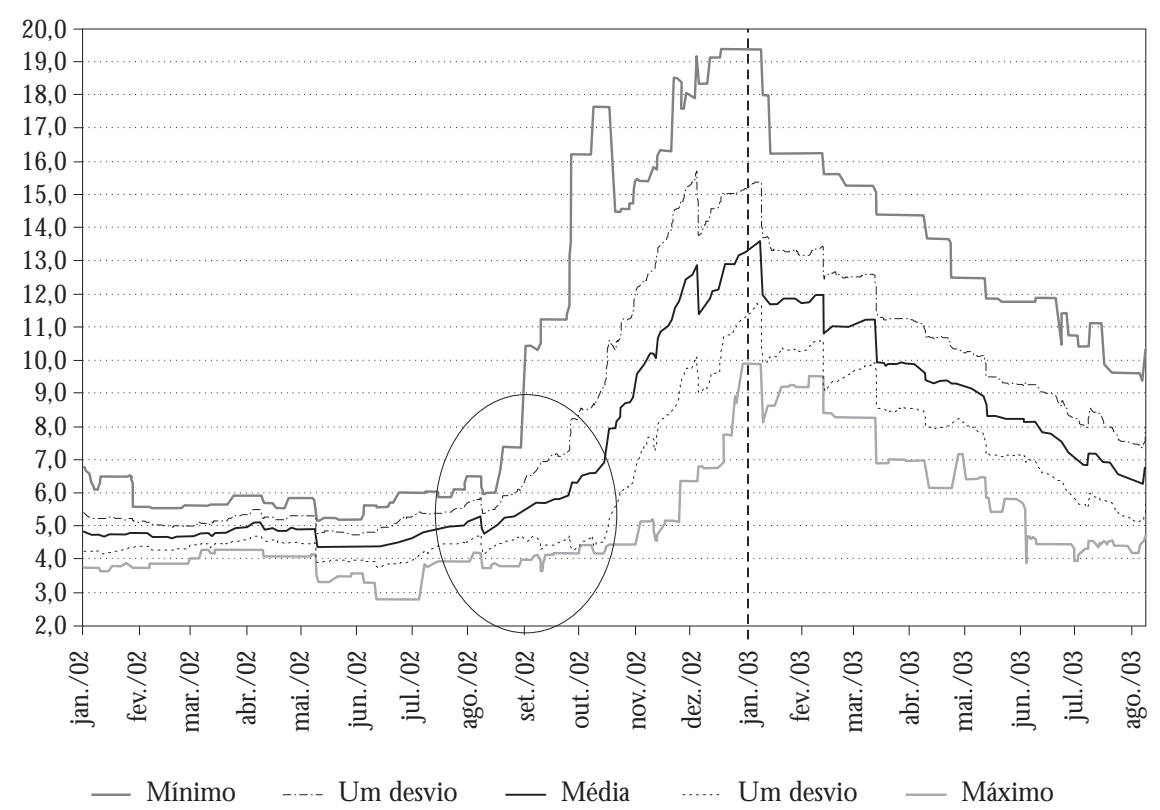

F onte: Elaboração dos autores a partir de dados disponíveis no sistema de recuperação de séries históricas em Banco C entral (www.bcb.gov.br), obtidos em agosto de 2003. 
0 efeito limitador representado pela instabilidade financeira durante o segundo mandato foi amplificado pelos desequilíbrios herdados do primeiro. Assim, o ambiente financeiro constituiu obstáculo a avanços mais profundos em direção ao crescimento sustentado e à maior geração de empregos.

\section{A redução da vulnerabilidade externa e interna}

Do ponto de vista da vulnerabilidade externa, o regime do segundo mandato produziu dois resultados importantes. Em primeiro lugar, teve início uma correção da distorção da apreciação cambial que impedia a sinalização para a expansão do setor exportador. Em segundo, melhorou a qualidade do financiamento dos déficits remanescentes.

FIGURA 7

M udança do Padrão de F inanciamento E xterno (1980-2003 parcial)

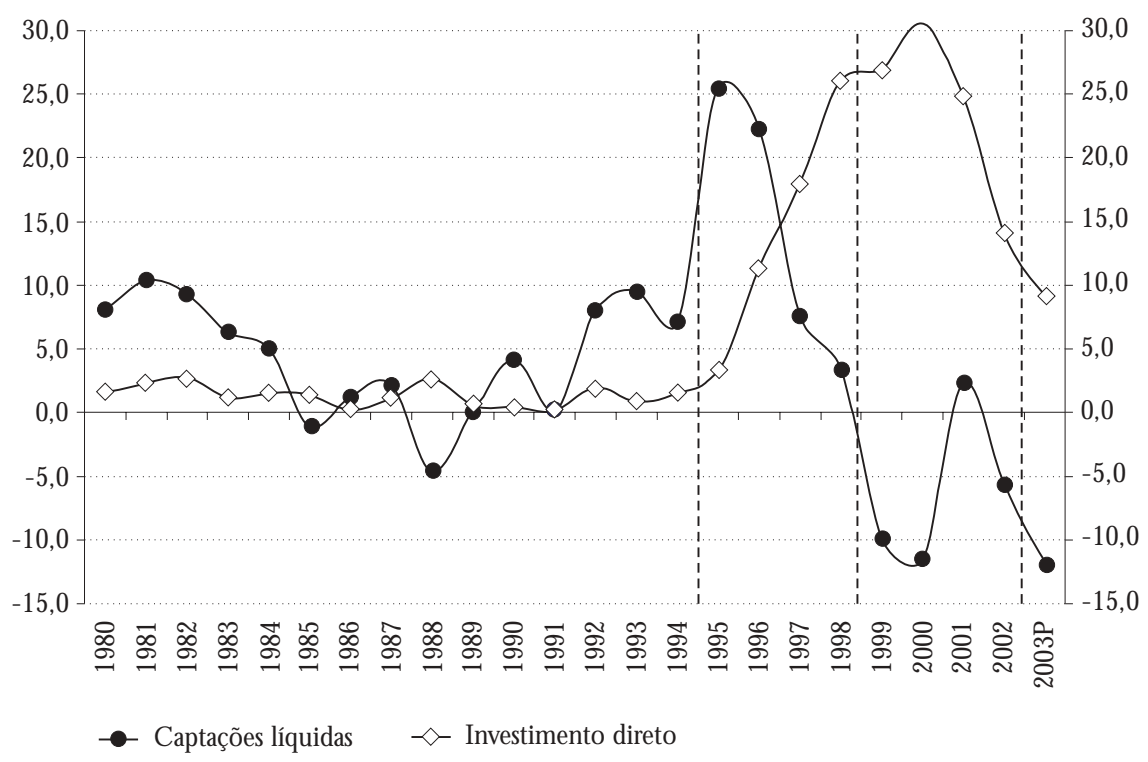

F onte: Elaboração dos autores a partir de dados disponíveis no sistema de recuperação de séries históricas em Banco C entral (www.bcb.gov.br), obtidos em agosto de 2003. As projeções foram obtidas em Banco Central (2003).

Como mostrado anteriormente, o déficit em conta corrente passou a apresentar uma trajetória declinante devido a dois componentes principais: as transações reais e as rendas. A razão entre dívida externa e exportações passou de 4,37, no fim de 1998, para 3,25, no fim de 2002. Este 
valor é ainda superior ao que se verificava no começo de 1995, mas se encontra em trajetória de queda.

No tocante ao financiamento externo (Figura 7), ganhou importância o investimento direto em detrimento das captações de outras naturezas (títulos, empréstimos e investimentos de portfólio).

\section{0 desafio do investimento e do crescimento}

O B rasil apresentou uma taxa de variação média da renda per capita de $1,2 \%$ no primeiro mandato de $\mathrm{FHC}$ e de $0,8 \%$ no segundo mandato, 0 que consiste em uma melhora se comparada à administração de Fernando Collor/ Itamar Franco (1990-1994), que apresentou um decréscimo de $0,4 \%$, mas não muito diferente do período de 1981 a 1983. A Tabela 1 apresenta uma comparação entre os dois períodos.

TABELA 1

Taxas de C resaimento: $M$ édias A nuais por Período (em \% ao ano)

\begin{tabular}{l|c|c}
\hline PERÍodo & VARIAÇÃo PIB REAL & VARIAÇÃo APROXIMAdA \\
\hline $1981-1989$ & DA REN DA PER CAPITA & 0,3 \\
$1990-1994$ & 2,3 & $-0,4$ \\
$1995-1998$ & 1,2 & 1,2 \\
$1999-2002$ & 2,6 & 0,8 \\
\hline
\end{tabular}

F onte: IBGE, I peadata e elaboração dos autores. D ados populacionais com base julho, conforme disponível no sistema de recuperação de dados do I peadata (www.ipeadata.gov.br).

TABELA 2

Taxas de $C$ resámento do PIB M undial, dos Países em D esenvolvimento e da $A$ mérica $L$ atina: $M$ édias A nuais por Período (em \% ao ano)

\begin{tabular}{l|c|c|c|c}
\hline Perído & Mundo & Países em desenvolvimento & América Latina & Brasil \\
\hline 1981-1989 & 3,2 & 4,2 & 1,3 & 2,3 \\
$1990-1994$ & 1,7 & 5,5 & 2,8 & 1,2 \\
$1995-1998$ & 2,9 & 5,5 & 3,0 & 2,6 \\
$1999-2002$ & 2,5 & 4,5 & 1,6 & 2,2 \\
\hline
\end{tabular}

F onte: IBGE, I peadata e elaboração dos autores. D ados populacionais com base julho, conforme disponível no sistema de recuperação de dados do I peadata (www.ipeadata.gov.br). 
É razoável contrastar o crescimento econômico brasileiro com o crescimento de outros países latino-americanose da economia mundial (Tabela 2). Pode-se observar que o crescimento da economia brasileira aumentou relativamente ao crescimento daA mérica Latina no segundo mandato, embora tenha seguido a tendência dos países em desenvolvimento e da economia mundial.

N ão seria exagero afirmar que, no período de 1999 a 2002, a tríplice mudança de regime contribuiu para criar as bases para um novo ciclo de crescimento, interrompido com a seqüência de choques que se sucederam em 2001 e 2002, com destaque para a crise do "apagão", para 0 ambiente internacional desfavorável e para as consequêencias da tensão préeleitoral doméstica.

Entre os principais desafios subjacentes à necessi dade de retomada do crescimento econômico sustentado está a recuperação da capacidade produtiva por meio de um ciclo de investimentos. Entre osváriosindicadores que mostram essa recuperação, pode-se observar o quantum do consumo aparente de máquinas, que mostrou forte incremento a partir do Plano R eal, sofreu os efeitos da crise de 1999, mas se recuperou até o nível próximo ao seu pico histórico, atingido em 1997 (Figura 8). A crise de 2002 representou novo golpe no consumo aparente de máquinas, que pode ser considerado como proxy do nível de investimento agregado.

A evolução dos investimentos no segundo mandato pode também ser observada por um indicador mais amplo, a Formação Bruta de $C$ apital Fixo. A Figura 9 mostra que houve três momentos em que a série sofreu um impacto negativo no segundo mandato, a saber, a crise da desvalorização de 1999, os choques de 2001, com destaque para a "crise do apagão"; e a tensão pré e pós-eleitoral de 2002. É evidente que o choque de maior impacto sobre essa série esteve relacionado com as incertezas pré e póseleitorais. No segundo trimestre de 2003, o nível da série retornou ao patamar prevalecente no começo do Plano R eal, quando os efeitos benéficos da estabilização e do novo ambiente da economia brasileira ainda não podiam ser plenamente sentidos no ritmo dos investimentos.

\section{0 legado do segundo mandato e os novos desafios}

A crítica ao período FH C é equivocada ao ignorar as profundas modificações que ocorreram nas políticas monetária e cambial a partir de 1999, caracterizadas neste trabalho como a tríplice mudança. 
FIGURA 8

Índice de C onsumo A parenteT rimestral de M áquinas (média 1990 = 100) (1991-2003)

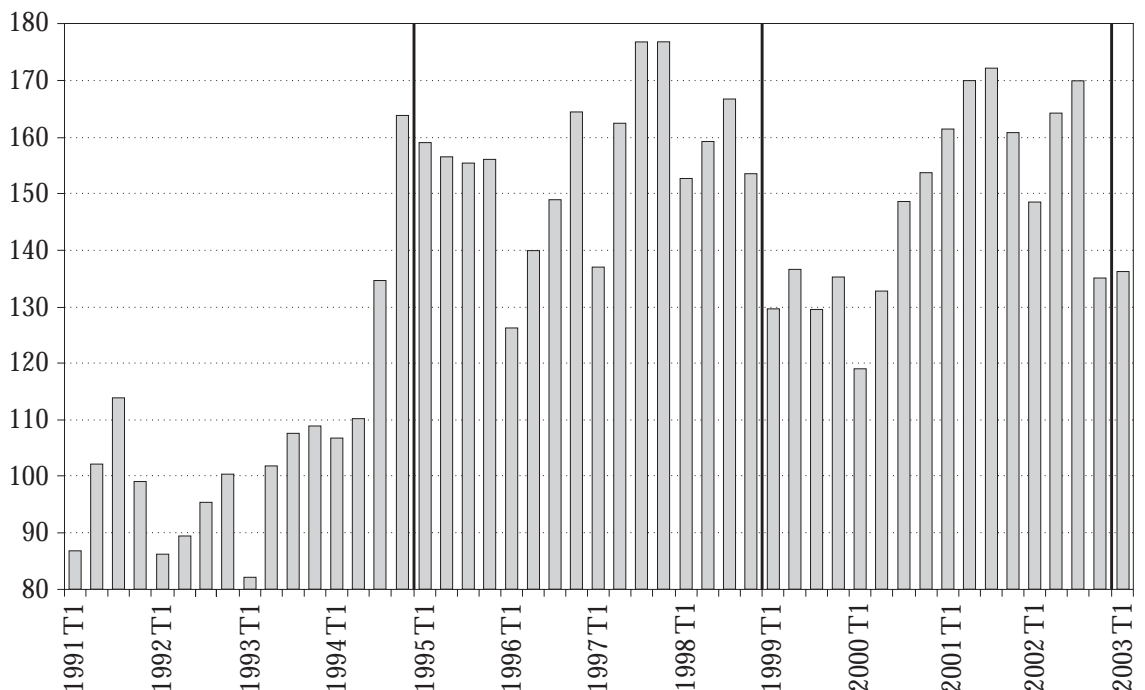

F onte: D ados obtidos no sistema I peadata de recuperação de dados (www.ipeadata. gov.br). Índice de base móvel construído pelo Instituto de Pesquisa EconômicaA plicada (I pea), a partir da produção de bens de capital da Pesquisa Industrial M ensal - Produção Física (PIM - PF); Fundação C entro de Estudos de Comércio (Funcex), índices de quantum das exportações e importações de bens de capital.

FIGURA 9

F ormação B ruta de C apital Fixo: ÍndiceT rimestral com A juste Saz onal (1998-2003)

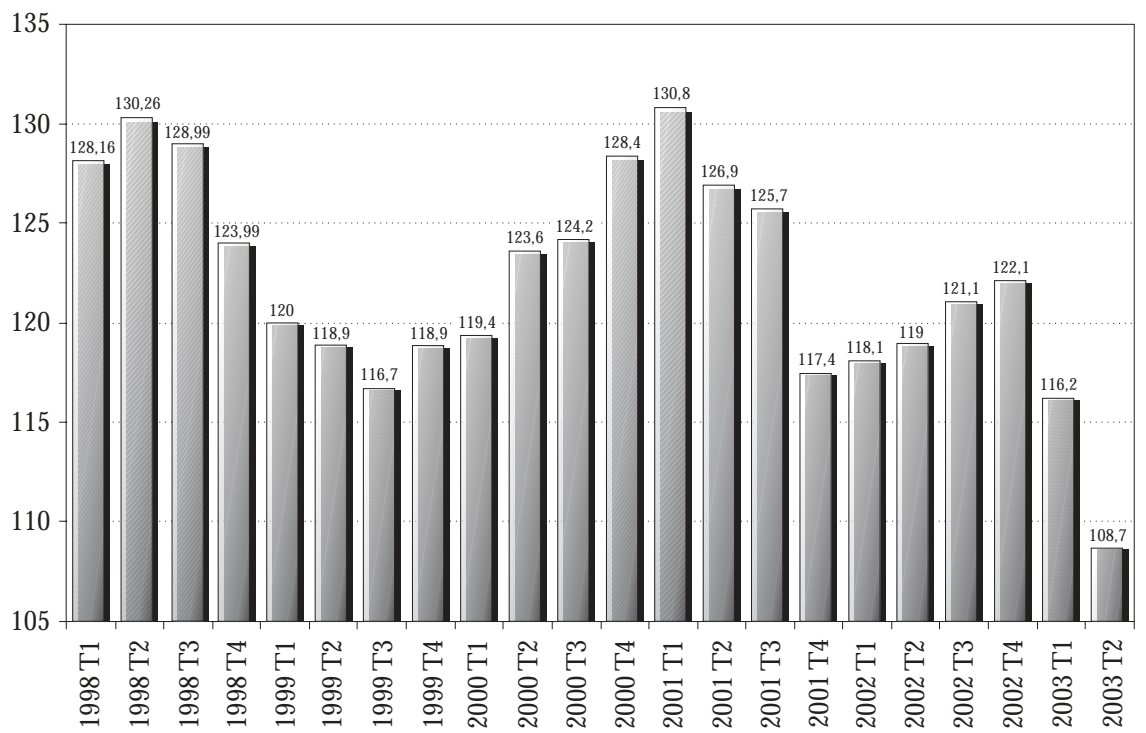

F onte: D ados primários obtidos no sistema de recuperação de dados do IBGE - Sidra em www.sidra.ibge. gov.br, obtidos em agosto de 2003. 
0 primeiro período $\mathrm{FHC}$ marcou a conquista da estabilidade de preços e a promoção de um novo marco regulatório nos segmentos de infra estrutura, embora com elevados custos do ponto de vista do equilíbrio do balanço de pagamentos. 0 período do segundo mandato marcou o restabelecimento de políticas monetária e cambial mais equilibradas, que criaram as condições de solvência tanto do setor público como do setor externo.

N o entanto, a sucessão de choques externos desfavoráveis, em presença de desequilíbrios que foram acumulados no esforço de estabilização durante o primeiro mandato, terminaram por comprometer o crescimento e reforçaram o processo de fadiga das reformas estruturais, especialmente a reforma tributária e o aperfeiçoamento do marco regulatório.Assim, o novo papel regulador do Estado foi implementado apenas parcialmente.Tais circunstâncias impediram uma elevação da taxa de investimento e uma retomada sólida da economia.

U ma herança positiva do segundo mandato foi a redução na volatilidade do produto. Em momentos anteriores, as crises internacionais levaram a contrações no PIB, seguidas de recuperações intensas. N o fim do segundo mandato, já se podia observar um quadro bastante diverso. M esmo submetida a intensos choques domésticos e externos a partir de 2001, a economia apresentou taxa de crescimento relativamente estável de 1,5\% ao ano em 2001 e 2002.

A Figura 10 mostra o comportamento da taxa de câmbio efetiva real. Verifica-se que o segundo mandato apresentou um nível de taxa de câmbio mais pró-exportação que os níveis observados no primeiro mandato FHC e no início do governo Lula.

Se fossem adotadas medidas adicionais no sentido de incentivar o investimento, sobretudo o investimento voltado para o setor exportador e nos segmentos de infra- estrutura, seria possivel conceber um ciclo de crescimento no período subseqüente. Esse potencial não veio a se concretizar devido a uma sequêencia de choques adversos, em especial a tensão préeleitoral de 2002.

Passada essa tensão, é hora de se pensar na retomada do ciclo de investimentose superar dificuldades como a fragilidade do ambiente regulatório. Este ainda não passou no teste da mudança de governo. D esde o início da nova administração, em 2003, 0 ambiente regulatório ainda está a exigir definição.

Persistem, contudo, fatores adicionais de vulnerabilidade e desafios para a economia brasileira. D estacam-se: 
FIGURA 10

Taxa de C âmbio E fetiva R eal (agosto de $1994=100$ )

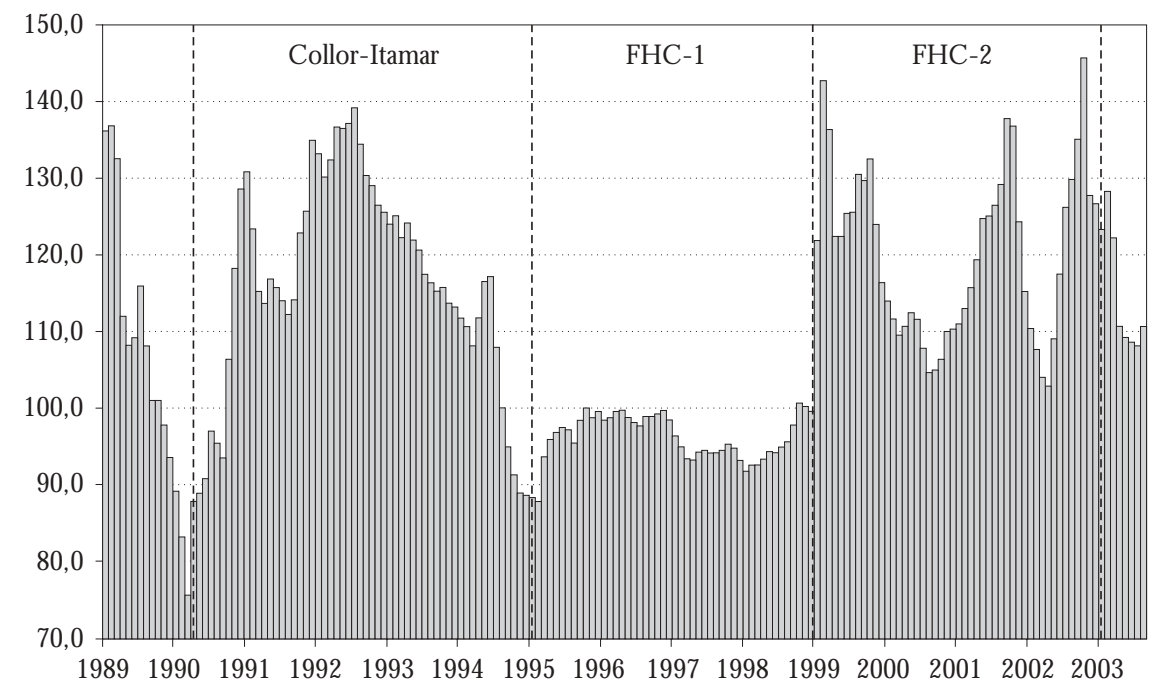

F onte: D ados primários da Fundação C entro de Estudos de Comércio Exterior (Funcex) relativos à cesta de treze moedas, obtidos em setembro de 2003.

- A consolidação definitiva da estabilidade fiscal.

- As necessidades de financiamento externo ainda elevadas, mesmo com a redução do déficit em conta corrente a níveis bastante confortáveis. M esmo que, por hipótese, o déficit em conta corrente seja zero, as necessidades de financiamento passam a ser representadas pelos vencimentos da dívida externa, que precisam ser pagos e novamente capta dos junto ao mercado internacional de capitais. No ano de 2003, 0 volume de amortizações da dívida externa de médio e longo prazo é da ordem de U $\$ \$ 27,2$ bilhões. D este montante, a expectativa é de que menos de um terço seja financiado mediante investimentos diretos, e 0 restante deverá ser obtido principalmente na forma de financiamentose emissão de títulos no mercado internacional de capitais.

- 0 padrão de financiamento externo, que se alterou positivamente durante o período $\mathrm{FHC}$, pode estar voltando à situação anterior. N esse período, o B rasil gal gou posições relativas no ranking mundial dos países receptores de investimento direto estrangeiro. $\mathrm{N}$ o começo da administração Lula, em 2003, o investimento direto no B rasil desacelerou-se à semelhança do investimento global no período; ainda assim, o B rasil, em contraposição a outros países, perdeu muitas posições. 
- A redução do patamar da taxa de juros, que permanece mais elevado do que em outros países em estágio similar de desenvolvimento e de níveis de classificação de risco.

Em especial, um desafio importante para a nova gestão macroeconômica é a superação da fadiga reformista do segundo mandato $\mathrm{FH} \mathrm{C}$. Em parte, tal fadiga está relacionada à ferrenha oposição exercida pela mesma corrente que hoje defende parte das reformas e que está no governo.

É importante evitar o equívoco de se fazer reformas sem objetivos claros. É notório, pelo início da administração Lula, que falta o fio condutor do desenvolvimento às propostas de reforma do governo. I sso é particularmente verdadeiro no caso da proposta de mudança do sistema tributário. As propostas iniciais tiveram como característica um viés de aumento da carga tributária, foram mantidas distorções sérias como a cumulatividade e a proposta não atacava a regressividade do sistema tributário.

Finalmente, cabe notar que a política macroeconômica não é tudo. $\mathrm{A}$ atenção às reformas deveria estar contida em um projeto maior voltado para o desenvolvimento. As reformas em si deveriam considerar a necessidade de maior estímulo à inversão produtiva, além de incentivo ao aumento da produtividade total dos fatores. M as, além das reformas, é essencial voltar a atenção para um projeto de desenvolvimento que inclua muitos aspectos de gestão da política econômica, como a necessidade de redução do risco regulatório no B rasil, que hoje constitui um dos principais entra ves ao investimento, à produção e ao emprego no país.

\section{Referências Bibliográficas}

Banco Central do Brasil. (2003), "N ota para a imprensa, setor externo”. B rasília, Banco Central, ago.

Bresser-Pereira, Luís C arlos. (2001), "A fragilidade que nasce da dependência externa". Valor 1000 , set.

C ASTRo, Jorge A brahão et al. (2003), "Evolução do gasto social federal: 1995-2001". Boletim Políticas Sociais. Instituto de Pesquisa EconômicaA plicada (I pea), D iretoria de Estudos Sociais, fev., Braślia.

G IAM BIAGI, Fábio. (2002), “D o déficit de metas às metas de déficit: a política fiscal do governo Fernando Henrique Cardoso - 1995/2002". Texto para D iscussão, 93, $R$ io de Janeiro, BN DES. 
O LiveIRA, G esner. (1999), "H isteria oportunista e realidade”. Folha de S. Paulo, 30/ 1, seção Tendências e D ebates.

\section{Resumo}

Este artigo discute a política macroeconômica do segundo governo de Fernando H enrique C ardoso (1999-2002), marcada por mudanças nas áreas fiscal, cambial e monetária. $\mathrm{N}$ a área fiscal, passou-se a gerar superávit primário e avançou-se nos esforços de reforma estrutural. $\mathrm{Na}$ área cambial, a passagem do regime de câmbio administrado para uma flutuação suja permitiu o ajuste do elevado déficit em conta corrente verificado no primeiro mandato. $\mathrm{N}$ a área monetária, o regime de metas de inflação substituiu a subordinação da política monetária à defesa do regime cambial. A pós tais alterações, o país passou a contar com um regime mais sustentável e transparente, cuja eficácia permaneceu limitada pela herança do regime anterior, gerador de desequilíbrios, e pelas instabilidades financeiras internacional e domésticas no período. A creditamos que o novo regime é adequado para a criação das condições no sentido da recuperação do investimento e do crescimento econômico, mas os principais desafios atuais residem mais em aspectos institucionais e regulatórios do que no regime de política macroeconômica.

Palavras-chave: Brasil; Política econômica; G overno Fernando H enrique C ardoso.

\section{Abstract}

This paper analyses the macroeconomic policy of FH C 's second government (19992002), that was marked by fiscal, foreign exchange and monetary changes. In the fiscal area, a primary superavit was generated and the efforts towards a structural reform were increased. R egarding foreign exchange policies, the move from administered exchange to one of dirty floating allowed for an adjustment of the high deficit in the current account that occurred in the first term of office. In the monetary field, the regime of inflation goals substituted the subordination of the monetary policy to the defense of the exchange regime. These alterations brought a more sustainable and transparent regime to the country, but its efficiency was limited due to the inheritance of the old regime, that generated unbalances and also to the international and domestic financial instabilities of the period. The new regime is adequate for the creation of conditions for the recovery of investments and for economic growth, but the main present chalenges have more to do with the institutional and regulatory aspects than with the macroeconomic policy regime.

Key words: Brazil; Economic policy; Fernando H enrique C ardoso' government.
Gesner O liveiraédoutor pela U niversidade da Califórnia, professor daEscola deAdministração de São Paulo da Fundação G etúlio Vargase sócio daTendências Consultoria Integrada.

Frederico A.Turolla é doutorando em Economia de Empresas pela Fundação G etúlio Vargas de São PauIo.É professor de Economia da Escola Superior de Propaganda e $M$ arketing edas Faculdades $\mathrm{O}$ swaldo $\mathrm{C}$ ruz. 